\title{
Interactive comment on "A new method for long-term source apportionment with time-dependent factor profiles and uncertainty assessment using SoFi Pro: application to one year of organic aerosol data" by Francesco Canonaco et al.
}

\section{Anonymous Referee \#1}

Received and published: 11 September 2020

The study of Canonaco et al. reports a significant method development for improved PMF based source apportionment by aerosol mass spectrometers and crucially aimed at long time series of measurements badly lacking in literature. Recommendations and Conclusions are fairly discussed and well balanced which should help future researchers in properly using the method. The paper is very well written, easy to follow and should be accepted after addressing mostly minor comments. 
Line 28. Past tense is more appropriate for the efforts in the past.

Line 39. ...and slightly higher mean concentrations...

Line 86. agricultural waste/residue burning.

Interactive

comment

Line 125. Average of the average (two-level averaging) reduces the weight of outliers and should generally be avoided, because it makes two-level averaged data not strictly compatible with one-level averaged tracers. Please elaborate on tracer data in relation to that. It is compounding of the fact that arithmetic averaging should not be applied to atmospheric variables in general (see later comment)

Line 144. biomass burning impact

Line 183. The resultant uncertainty of individual uncertainties can be calculated by the square root of squared sum, i.e. three individual uncertainties of $10 \%$, result in $17 \%$. So the resultant uncertainty will always be higher, not "might be slightly outside the defined a-range".

Line 202. Section 0 typo here and later several times. Then Line 305.

Line 212. missing dot

Line 326. Criterion of highest possible correlation coefficient and maximal data coverage are working against each other, so must be a compromise. What was it? It is not clear why 0.6 or 0.8 is best and what data coverage does it correspond to?

Line 333. If COA is well established it should peak every single day just like traffic factor during rush hour. If COA was not resolved, maybe its not very real. I was always concerned about this factor being a combination of true COA and being a waste basket for increasingly processed aerosol during midday when photochemical activity is at its highest. That is why tracer $\mathrm{m} / \mathrm{z}$ as in BBOA case would yield much more credible approach.

Printer-friendly version

Discussion paper 
Line 375. Given the fact that aerosol properties are lognormally distributed due to fundamental principles, using arithmetic averages is not appropriate. The study is very AMTD much grounded in mathematics and statistics where proper usage of terms is not only expected but mandatory. I understand that historically inappropriate usage is continuing forever. When noted the issue is ignored while when demanded is considered harsh.

Interactive comment

Line 392. If COA spikes are barbecue related do they all occur during weekend as barbecues are rare during weekdays.

Line 429. ...as the problematic data yields eBCxb concentrations near zero anyway...

Line 461 ....likely indicating significant impact of biomass burning.

Line 492. ...last third of the study period...

Line 502. Here is an example of mixing together lognormal and normal (sigma and mean) distributions.

Line 535. ...to achieve complete apportionment.

Figure 2. b) typed twice instead of c)

Figure 3. . . clogging of ACSM inlet orifice.

Figure 5. ...truncated at $\mathrm{m} / \mathrm{z} 125$ ?

Figure 6. ...of important $\mathrm{m} / \mathrm{z}$ tracers.

Interactive comment on Atmos. Meas. Tech. Discuss., doi:10.5194/amt-2020-204, 2020. 